\title{
Quantitative and Qualitative Assessment of Phytochemicals in Methanolic Extracts of Hurricane Weed (Phyllanthus amarus Schumach. \&Thonn) Plant
}

\section{${ }^{* 1}$ AMEEN, OA; ${ }^{2} \mathrm{HAMID}, \mathrm{AA} ;{ }^{2}$ YUSUF, Q; ${ }^{1} \mathrm{NJOKU}$, OG; OSENI, TO; ${ }^{1,3} \mathrm{JAMIU}, \mathrm{W}$}

\author{
${ }^{*}$ Department of Science Laboratory Technology, Kwara State Polytechnic Ilorin, Kwara State, Nigeria \\ ${ }^{2}$ Department of Chemistry, University of Ilorin, Ilorin, Kwara State. Nigeria \\ ${ }^{3}$ Department of Industrial Chemistry, University of Ilorin, Ilorin, Kwara State. Nigeria \\ *Corresponding Author Email: waschem06@ gmail.com
}

\begin{abstract}
The phytocomponents of the leaf and root extracts of Phyllanthus amarus (Euphorbiaceae) were studied. The constituents of the leaves and roots were identified and quantified by using GC-MS. Result from the phytochemical analyses showed the presence of saponins, tannins, phenolics, anthocyanins, and glycosides in both leaves and root of the plant. Alkaloids and triterpenoids were, however only absent in the root of $P$. amarus but present in the leaves of the plant. Flavonoids, coumarins and steroids were absent in the leaves but present in the root part. The mean concentration of the phytochemicals investigated in leaves are $0.73 \pm 0.01 \%, 1.85 \pm 0.03 \%, 1.12 \pm 0.01 \%, 1.80 \pm 0.01 \%$, $1.59 \pm 0.50 \%, 0.13 \pm 0.10 \%$, and $0.86 \pm 0.01 \%$, for saponins, tannins, phenolics, anthocyanins, alkaloids, triterpenoids, and glycosides respectively, while the mean concentration of the phytochemicals investigated in roots are $0.91 \pm 0.01 \%$, $1.53 \pm 0.03 \%, 0.70 \pm 0.01 \%, 2.97 \pm 0.10 \%, 2.47 \pm 0.03 \%, 0.62 \pm 0.01 \%, 0.90 \pm 0.01 \%$ and $2.02 \pm 0.10 \%$ for saponins, tannins, phenolics, steroids, flavonoids, anthocyanins, glycosides and coumarins respectively. Furthermore, the GC-MS analysis of methanol extracts of the leaves and root of $P$. amarus revealed the presence of three medicinally important bioactive compounds, which are: 9-Octadecenoic acid which has percentage of abundance of $92.23 \%$ and $82.46 \%$ in leaves and roots of the plant respectively, followed by n-Hexadecanoic acid and Tetradecanoic acid with their corresponding percentage of abundance of $7.7 \%$ and $17.54 \%$ for leaves and root. These analytical results suggest the plantto possess a significant role in phyto-medicine. The importance of this plant was discussed in line with the role they play in ethnomedicinal life of the people.
\end{abstract}

DOI: https://dx.doi.org/10.4314/jasem.v25i2.4

Copyright: Copyright $\odot 2021$ Ameen et al. This is an open access article distributed under the Creative Commons Attribution License (CCL), which permits unrestricted use, distribution, and reproduction in any medium, provided the original work is properly cited.

Dates: Received: 12 December 2020; Revised: 26 January 2021; Accepted: 12 February 2021

Keywords: Phyllanthus amarus; Phytochemicals; GC-MS; methanolic extract; Phytocomponents

Phyllanthus amarus are slender, leaf-bearing branchlets, distichous leaves that are sub-sessile elliptic-oblong, obtuse, rounded base and a branching annual glabrous herb which is $30-60 \mathrm{~cm}$ high (Itoro et al., 2013). It has an approximate of 800 species which are found in tropical and subtropical countries of the world (Mazumder et al., 2006; Tahseen and Mishra, 2013). The plants are monoecious. It has smooth cylindrical stem $(1.5-2 \mathrm{~mm})$ thick and deciduous horizontal branchlets $(4-12 \mathrm{~cm})$ long and $0.5 \mathrm{~cm}$ thick, with 15 to 30 leaves. The leaves are simple, alternate or opposite and leathery. Itis one of the medicinally important plants belonging to Euphorbiaceae commonly known as "stone breaker". In Yoruba languages, the plant is locally called 'EyinOlobe'. Phyllanthus amarus have some common names in North, Central and South America as seed-under-leaf, black catnip, carry-me seed, egg woman, stone breaker, hurricane weed, quinine creole, quinine weed (Morton, 1981). In appearance, phytochemical structure and history of use, $P$. amarusis sometimes mistaken and wrongly identified with the closely related to P. niruri (Morton, 1981). Phyllanthus amarus plant is widely used (Lewis and Elvin-Lewis, 2007). An infusion is considered a good tonic, diuretic and antipyretic. Gonorrhea, diarrhea, dysentery, and stomach-ache, pain in the sides, haemorrhoids and absence of menstruation or female sterility can be treated with decoction of the only the leaves part of the Phyllanthus amarus plant. Application of suppository of the leaf paste to the vagina is used to treat absence of menstruation and polyps (Bharatiya, 1992; Akah and Nwambie, 1994). The mixture of leaf sap with palm oil or not, is applied as ear drops to treat otitis and applied to abscesses, sores and wounds. The use and dependence on plants as medicines by man has been in existence since time immemorial and man continues to search for plants as drug for a particular disease within his reach. The white spots on skin and jaundice can be cured by fresh leaf paste of $P$. amarus which has wound healing capacity. The stem juice is also used as wound healers. The urinary problems \& swelling of liver can be treated by the whole plant extract. Stomach pain can be cured by using the root 
extract of $P$. amarus. Externally, the application of flower paste of $P$. amarus plant as antidote is used to fight against snake bite (Chandewar and Dhongade, 2013, Adegoke et al., 2010; Patel et al., 2011; Zingare, 2013). Because of the phytochemicals in the plant extract target the biochemical pathway, it is now implies that herbal medicines are safer than synthetic medicines (Zaidan et al., 2005). There are more than a thousand known phytochemicals in the plant. Secondary metabolites from plants are an important source of drugs since ancient times and now almost $50 \%$ of the practical drugs used are derived from natural sources. Secondary metabolites of plants like alkaloids, tannins, flavonoids, saponins, anthocyanins, steroids, phenolics, coumarins, cardiac glycosides and cyanogenic glycosides etc. are of pivotal importance. At least 12,000 such compounds have been isolated so far, a number estimated to be less than $10 \%$ of the total (Tapsell et al., 2006; Lai and Roy, 2004). Traditionally, the leaves of the plant were used as antidiarrhoeal, antioxidant, analgesic, antiinflammatory, antimicrobial, antihypertensive, antidiabetic and hypolipidemic properties (Adeneye, 2006; Odetola and Akojenu, 2000). Gas Chromatography-Mass Spectrophotometer (GC-MS), is the best technique to identify the bioactive constituents of long chain hydrocarbons, alcohols, acids, esters, alkaloids, steroids, amino acid and nitro compounds (Muthulakshmi et al., 2012). The objective of the study is to quantify and identify the phytocomponents present in the methanolic extracts of leaves and roots of $P$. amarus plant.

\section{MATERIALS AND METHODS}

Collection of Leaves and Roots of Phyllanthus amarus: Fresh plant leaves and roots of Phyllanthus amarus were collected within Ilorin, Kwara State. The leaves and roots were washed thoroughly 2-3 times, air dried and later oven dried at room temperature $\left(26^{\circ} \mathrm{C}\right)$ for seven days. The dried leaves and roots were pounded separately into a homogenous powder using mortar and pestle. The plant materials were stored at $4^{\circ} \mathrm{C}$ in tight air labelled container bottle for extraction use.

Extraction of Leaves and Roots of Phyllanthus amarus: Methanol was used for the extraction. A $10 \mathrm{~g}$ each of the dry plant parts (leaves and roots) were soaked in $50 \mathrm{ml}$ of methanol in a container separately at room temperature for three days $(72 \mathrm{hrs})$. The extracts were filtered using a Whatmann filter paper No. $42(125 \mathrm{~mm})$, and then through cotton wool. The extracts were evaporated into dryness using a hot water bath for $72 \mathrm{hrs}$, and were then stored in the refrigerator for further use.
Phytochemical Screening: Phytochemical screenings were carried out quantitatively using methanolic extract to identify various constituents by following standard methods.

Determination of Saponin: A $1 \mathrm{~g}$ of the dried sample that had passed through $125 \mathrm{~mm}$ sieve was transferred into a $250 \mathrm{ml}$ beaker, and $100 \mathrm{ml}$ of isobutyl alcohol was added. The mixture was swirled for 5 minutes and filtered. The filtrate was transferred into a $100 \mathrm{ml}$ beaker containing $20 \mathrm{ml}$ of $40 \%$ saturated solution of $\mathrm{MgCO}_{3}$.About $1 \mathrm{ml}$ of the colourless filtrate was pipette into a $50 \mathrm{ml}$ volumetric flask and $2 \mathrm{ml}$ of $5 \%$ $\mathrm{FeCl}_{3}$ solution was added and made up to the marked level with distilled water. This was then allowed to stand for 30 minutes for a blood red colour to develop. Percentage saponin was calculated using the formula:

$$
\% \text { Saponin }=\frac{\text { AS } \times \text { AG } \times \text { DF }}{\text { Wt of sample } \times 10,000}
$$

Where AS =Absorbance of sample; $A G=$ Average gradient; $\mathrm{DF}=$ Dilution factor and $\mathrm{Wt}$ of sample = Weight of sample

Determination of Tannin: A $20 \mathrm{ml}$ of $50 \%$ methanol was added to $0.2 \mathrm{~g}$ of sample in the $50 \mathrm{ml}$ beaker. The mixture was covered with paraflim and placed in a water bath at $77-80^{\circ} \mathrm{C}$ for an hour. After cooled, the extract was filtered using a double layered Whatman No. 41 filter paper and transferred into a $100 \mathrm{ml}$ volumetric flask. $20 \mathrm{ml}$ of distilled water, $2.5 \mathrm{ml}$ FolinDenis reagent and $10 \mathrm{ml}$ of $17 \% \mathrm{Na}_{2} \mathrm{CO}_{3}$ were added and mixed properly. The mixture was made up to volume with distilled water and allowed to stand for 20 minutes. A bluish-green colour will develop at the end of range. The concentration of tannins was detected through the use of TGP 210 Buck atomic absorption spectrophotometer (AAS).

Determination of Phenol: The aliquots of the extract was transferred into a test tube and made up to the volume of $1 \mathrm{ml}$ with distilled water. Then $0.5 \mathrm{ml}$ of Folin-Ciocalteu reagent (1:1 with water) and $2.5 \mathrm{ml}$ of sodium carbonate solution $(20 \%)$ were added sequentially to the test tube. Soon after overtaking the reaction mixture, the tubes were placed in the dark for 40 minutes and the absorbance was recorded at $725 \mathrm{~nm}$ against the reagent blank. The total phenolic content was calculated and expressed as gallic acid equivalent in percentage of extract.

Determination of Steroid: A $0.05 \mathrm{~g}$ of sample extract was added into a $100 \mathrm{ml}$ beaker; $20 \mathrm{ml}$ of chloroformmethanol (2:1) mixture was added to the extract. The mixture was shaken for 30 minutes until it free of 
steroids. $1 \mathrm{ml}$ of the filtrate was pipette into $30 \mathrm{ml}$ test tube and $5 \mathrm{ml}$ of alcoholic $\mathrm{KOH}$ was added and shaken thoroughly to obtain a homogenous mixture. The mixture was later placed in a water bath set at $37^{\circ} \mathrm{C}$ $40^{\circ} \mathrm{C}$ for 90 minutes. It was cooled to room temperature and $10 \mathrm{ml}$ of petroleum ether added followed by the addition of $5 \mathrm{ml}$ distilled water. This was evaporated to dryness on the water bath, $6 \mathrm{ml}$ of Liebermann Buchard reagent was added to the residue in dry bottle and absorbance taken at a wavelength of $620 \mathrm{~nm}$ on a spectronic 21D digital spectrophotometer.

Determination of Flavonoid: A $1 \mathrm{ml}$ of extract was added to $10 \mathrm{~mL}$ volumetric flask containing $4 \mathrm{ml}$ of distilled water, then, $0.3 \mathrm{ml}$ of $5 \% \mathrm{NaNO}_{2}$ was added. After 5 minutes, $0.3 \mathrm{ml}$ of $10 \% \mathrm{AlCl}_{3}$ was added. At $6^{\text {th }}$ minutes, $2 \mathrm{ml}$ of $1 \mathrm{M} \mathrm{NaOH}$ was added and the total volume was made up to $10 \mathrm{ml}$ with distilled water. The solution was mixed well and the absorbance was measured against prepared reagent blank at 510nm. Total flavonoid content was expressed as percentage.

Determination of Glycosides: A $10 \mathrm{ml}$ of extract was pipette into a $250 \mathrm{ml}$ conical flask; $50 \mathrm{ml}$ chloroform was added and shaken on a Vortex Mixer for one hour. The mixture was filtered into a conical flask, $10 \mathrm{ml}$ pyridine and $2 \mathrm{ml}$ of $2 \%$ sodium nitroprusside were added and shaken thoroughly for 10 minutes. $3 \mathrm{ml}$ of $20 \% \mathrm{NaOH}$ was later added to develop a brownish yellow colour. The absorbance of sample as well as standards was read on a spectronic 21D digital spectrophotometer at a wavelength of $510 \mathrm{~nm}$. Percentage Glycosides was calculated using the formula:

$$
\% \text { Glycosine }=\frac{\text { AS } \times \text { AG } \times \text { DF }}{\text { Wt of sample } \times 10,000}
$$

Where AS =Absorbance of sample; $\mathrm{AG}=$ Average gradient; $\mathrm{DF}=$ Dilution factor and $\mathrm{Wt}$ of sample = Weight of sample

Determination of Coumarin: A $0.5 \mathrm{ml}$ of $5 \mathrm{~N} \mathrm{NaOH}$ was added to the solution of $1 \mathrm{ml}$ of the extract $(0.5 \mathrm{~g}$ in $1 \mathrm{ml}$ of methanol). The mixture was heated at $80^{\circ} \mathrm{C}$ for 5 minutes. After cooled, $0.75 \mathrm{ml}$ of $5 \mathrm{~N} \mathrm{H}_{2} \mathrm{SO}_{4}$ was added and mixed thoroughly, then, $0.25 \mathrm{~g}$ of anhydrous $\mathrm{NaHCO}_{3}$ was also added and transfer to the extractor and make up to $50 \mathrm{ml}$ with petroleum ether for 3 hours. About $20 \mathrm{ml}$ of water was added to the petroleum ether extract and carefully evaporate the petroleum ether in a water bath at $50-55^{\circ} \mathrm{C}$. The aqueous solution was transferred to a volumetric flask and make up to $50 \mathrm{ml}$ with continuous mixing. $25 \mathrm{ml}$ of aqueous solution was pipette into a flask and $1 \% \mathrm{Na}_{2} \mathrm{CO}_{3}$ solution was added and heated in a water bath at $85^{\circ} \mathrm{C}$ for 15 minutes and cooled. $5 \mathrm{ml}$ of the diazonium solution was added, and stand for 2 hours. The absorbance at $540 \mathrm{~nm}$ against reagent blank was used.

Determination of Alkaloids: A $2 \mathrm{~g}$ of the finely ground sample was transferred into $100 \mathrm{ml}$ beaker and $20 \mathrm{ml}$ of $80 \%$ absolute alcohol was added to give a smooth paste. The mixture was transferred to a $250 \mathrm{ml}$ flask and more alcohol was added to make up to the mark and about $1 \mathrm{~g}$ of magnesium oxide was then added. The mixture was digested in a boiling water bath for one and half hour under a refluxed air condenser with occasional shaking. The mixture was filtered while hot through a Buchner funnel. The residue was poured back into the flask and re-digested for another thirty minutes with $50 \mathrm{ml}$ alcohol after which the alcohol was evaporated. Distilled water was added to replace the lost alcohol. When all alcohol had evaporated, 3 drops of $10 \% \mathrm{HCl}$ was added. The whole solution was later transferred into $250 \mathrm{ml}$ volumetric flask; $5 \mathrm{ml}$ of Zinc acetate solution and $5 \mathrm{ml}$ of potassium ferric cyanide solution were thoroughly mixed together to give a homogenous mixture. The flask was allowed to stand for a few minutes, filtered through a dry filter paper and $10 \mathrm{ml}$ of the filtrate was transferred into a separating funnel and alkaloids present were extracted vigorously by shaking with five successive portions of chloroform. The residue obtained was dissolved in 10 $\mathrm{ml}$ of hot distilled water and transferred into a Kjeldahl tube with the addition of $0.2 \mathrm{~g}$ of selenium for digestion to a clear colourless solution. The clear colourless solution was used to determine Nitrogen using Kjeldahl distillation apparatus, the distillate was back titrated with $0.01 \mathrm{~N} \mathrm{HCl}$ and the titre value obtained was used to calculate the \% Nitrogen using the formulae:

$$
\% \text { Nitrogen }=\frac{\mathrm{TV} \times \mathrm{AM} \mathrm{N} \times 100}{\text { weight of sample }(\mathrm{mg})}
$$

$\mathrm{TV}=$ titre value AM N = atomic mass of nitrogen of $\mathrm{HCl}$

$$
\% \text { Alkaloid }=\% \text { Nitrogen } \times 3.26
$$

Preparation of Samples for Gas ChromatographyMass Spectrum (GC-MS) Analysis: GC-MS analysis was carried out using 7890A GC system, 5675C Inert MSD with triple-Axis detector. The column has a length of $30 \mathrm{~m}$ with an internal diameter of $0.2 \mu \mathrm{m}$ and a thickness of $250 \mu \mathrm{m}$, treated with phenyl methyl silox. Other GC-MS conditions are ion source temperature $(\mathrm{EI}), 250^{\circ} \mathrm{C}$, interface temperature; $300^{\circ} \mathrm{C}$, pressure; 16.2 psia, out time, $1.8 \mathrm{~mm}, 1 \mu \mathrm{l}$ injector in split mode with split ratio 1:50 with injection temperature of $300^{\circ} \mathrm{C}$, the column temperature started at $35^{\circ} \mathrm{C}$ for 5 minutes and changed to $150^{\circ} \mathrm{C}$ at the rate of $4^{0} \mathrm{C} / \mathrm{min}$, the temperature was raised to $250^{\circ} \mathrm{C}$ at the 
rate of $20^{\circ} \mathrm{C} / \mathrm{min}$ and held for 5 minutes. The total elution was 47.5 minutes. Ms Solution software provided by supplier was used to control the system and to acquire the data; identification of the compounds was carried out by comparing the mass spectra obtained with those of the standard mass spectra from National Institute of Standard and Technology (NIST) database. The identity of the spectra above $95 \%$ was used to ascertain the name, molecular weight and structure of the components in the leaves and roots of Phyllanthus amarus.

Isolation and Identification of Components: A glass column was washed, dried and clamped vertically on to a retort stand. The glass column was then packed with silica gel of $60(0.063-0.200 \mathrm{~mm})$ meshes was slowly poured into the column with the tap opened such that it gently settled on a uniform fashion. The column was constantly tapped to get rid of any trapped air bubbles and also ensure a leveled layer of the absorbent. The solvent system used in eluting the column started with $100 \%$ n-hexane, hexane/ethyl acetate $(9: 1), \quad(8: 2),(6: 4),(5: 5),(2: 8), \quad 100 \%$ ethyl acetate and methanol $(9: 1),(8: 2),(6: 4),(5: 5)$. A partially pure pale white compound was obtained $\left(\mathrm{SCO}_{3}, 40 \mathrm{mg}, 100 \%\right.$ ethyl acetate). The isolate $\mathrm{SCO}_{3}$ was subjected to IR and GC-MS analysis.

\section{RESULTS AND DISCUSSION}

Phytochemicals Screening of Methanolic Extracts: Quantitative screening using methanolic extract of plant indicated the presence of some of the phytochemical constituents in leaves and roots of $P$. amarus.

The total numbers of phytochemicals present in the leaves were seven (7) while eight (8) phytochemicals were present in the roots. Quantitative analysis of phytochemicals in the Phyllanthus amarus plants indicated that the both leaves and roots contain the phytochemicals in varying amounts.

The mean values of saponins, tannins, phenolics, anthocyanins, alkaloids, triterpenoids and glycosides in leaves are $0.73 \pm 0.01 \%, 1.85 \pm 0.03 \%, 1.12 \pm 0.01 \%$, $1.80 \pm 0.01 \%, 1.59 \pm 0.50 \%, 0.13 \pm 0.10 \%$ and $0.86 \pm$ $0.01 \%$ respectively. The phytochemical with the highest quantity were tannins, followed by anthocyanins, alkaloids, phenolics, glycosides, saponins and triterpenoids respectively (Table 1).

The mean values of saponins, tannins, phenolics, steroids, flavonoids, anthocyanins, glycosides and coumarins in roots are $0.91 \pm 0.01 \%, 1.53 \pm 0.03 \%$, $0.70 \pm 0.01 \%, 2.97 \pm 0.10 \%, 2.47 \pm 0.03 \%, 0.62 \pm 0.01 \%$, $0.90 \pm 0.01 \%$ and $2.02 \pm 0.18 \%$ respectively (Table 1 ).
Steroids have the highest quantity, followed by flavonoids, coumarins, tannins, saponins, glycosides, phenolics and anthocyanins.

Table 1: Quantitative estimation of secondary metabolites in the

\begin{tabular}{lll}
\multicolumn{3}{c}{ plant parts studied. } \\
\hline Phytochemicals & Leaves $(\%)$ & Roots $(\%)$ \\
\hline Saponins & $0.73 \pm 0.01$ & $0.91 \pm 0.01$ \\
Tannins & $1.85 \pm 0.03$ & $1.53 \pm 0.03$ \\
Phenolics & $1.12 \pm 0.01$ & $0.70 \pm 0.01$ \\
Steroids & - & $2.97 \pm 0.10$ \\
Flavonoids & - & $2.47 \pm 0.03$ \\
Anthocyanin & $1.80 \pm 0.01$ & $0.62 \pm 0.01$ \\
Alkaloids & $1.59 \pm 0.50$ & - \\
Triterpenoids & $0.13 \pm 0.10$ & - \\
Glycosides & $0.86 \pm 0.01$ & $0.90 \pm 0.01$ \\
Coumarins & - & $2.02 \pm 0.10$ \\
\hline
\end{tabular}

Finar, 2009, reported that Saponins are active as expectorant and is very useful in the treatment of upper respiratory tract inflammations; they also have antidiabetic and anti-fungal properties. Saponins, often referred to as natural detergent due to their foamy nature, also possess anti carcinogenic properties, immune modulation activities and regulation of cells proliferation as well as inhibition of the growth of cancer cells and cholesterol lowering activity (Jimoh and Oladji, 2005). The methanolic extract of leaves and roots of Phyllanthu samarus studied are involved in saponin expectorant action which is very useful in the management of upper respiratory tract inflammation; saponins present in plants are cardiotonic in nature and are reported to have antidiabetic and anti-fungal properties. It has been reported that tannins possess physiological astringent and haemostatic properties, which hasten wound healing and ameliorated inflamed mucus membrane. They have important roles such as stable and potent anti-oxidants (Trease and Evans, 2009; Ogunleye and Ibitoye, 2003). Tannins also have been reported to form complexes with digestive enzymes thus reducing the digestibility of proteins in foods (Amelio, 1999). Okwu and Omodamino, 2005 also reported that, plants that contain phenol could be used as antiinflammatory, immune enhancers and hormone modulators.

According to Kittakoop et al., (2014), alkaloids have a wide range of pharmacological properties including antimalarial, antiasthma, anticancer properties. Davis and Heywood, 2013 reported the used in medicine especially the steroidal alkaloids and also show considerable pharmacological activity. It was also reported to have cholinomimetic, vasodilatory, antiarrhythmic, anti-hyperglycemic activities (Qiu et al., 2014), analgesic and antibacterial properties (Russo et al., 2013; Cushnie et al., 2014) though they can be toxic too (Robbers et al., 1996). Studies have shown 
that the plant parts studied have the tendency to treat these ailments because of the presence of alkaloids in the leaves part. O'Neil et al., (2000) reported that the root part of the plant possessed anti-oxidant, antiinflammatory, anti-allergic, anti-carcinogenic, antimicrobial, hepatoprotective and anti-viral properties due to the presence of flavonoid. Flavonoids are platelets aggregation which helps to prevent platelets sickness (Okwu et al., 2006). The presence of coumarins in root part of $P$. amarus enable this plant to carry out various pharmacological activities such as oedema modification, faster reabsorption of oedematous fluids, treatment of lymphedema, etc. (Casley-Smith, 1993).

Gas Chromatography-Mass Spectrum (GC-MS) Analysis: By GC-MS analysis, 3 compounds were identified in methanolic extract of leaf and root parts of $P$. amarus. The spectrum profile of GC-MS confirmed the presence of 3 components with the retention time. The individual fragmentation patterns of the components were described below. Compound 1 was identified in the leaves and roots as nHexadecanoic acid also known as Palmitic acid which is a long chain saturated fatty acid with a molecular formula of $\mathrm{C}_{16} \mathrm{H}_{32} \mathrm{O}_{2}$ and molecular weight of 256.43 $\mathrm{g} / \mathrm{mol}$. The compound comprised $7.70 \%$ of the extract and the mass spectrum of the compound with retention time 38.991 minutes in the leaves while in the roots, its comprised $17.54 \%$ of the extract and the mass spectrum of the compound with retention time 38.997 minutes (Table 2). Compound 2 was identified as Tetradecanoic acid also known as Myristic acid, saturated 14-carbon fatty acid which has a molecular formula of $\mathrm{C}_{14} \mathrm{H}_{28} \mathrm{O}_{2}$ and molecular weight of 228.38 $\mathrm{g} / \mathrm{mol}$. The compound comprised $7.70 \%$ of the extract and the mass spectrum of the compound with retention time $38.991 \mathrm{~min}$ in the leaves while in the roots, its comprised $17.54 \%$ of the extract and the mass spectrum of the compound with retention time 38.997 minutes. Compound 3 was identified as 9Octadecenoic acid also known as oleic acid which is a long chain unsaturated fatty acid with a molecular formula of $\mathrm{C}_{18} \mathrm{H}_{34} \mathrm{O}_{2}$ and molecular weight of 282.47 $\mathrm{g} / \mathrm{mol}$. The compound comprised $85.56 \%$ of the extract and the mass spectrum of the compound with retention time 40.135 minutes in the leaves while in the roots, its comprised $64.92 \%$ of the extract and the mass spectrum of the compound with retention time 40.129 minutes (Table 2).

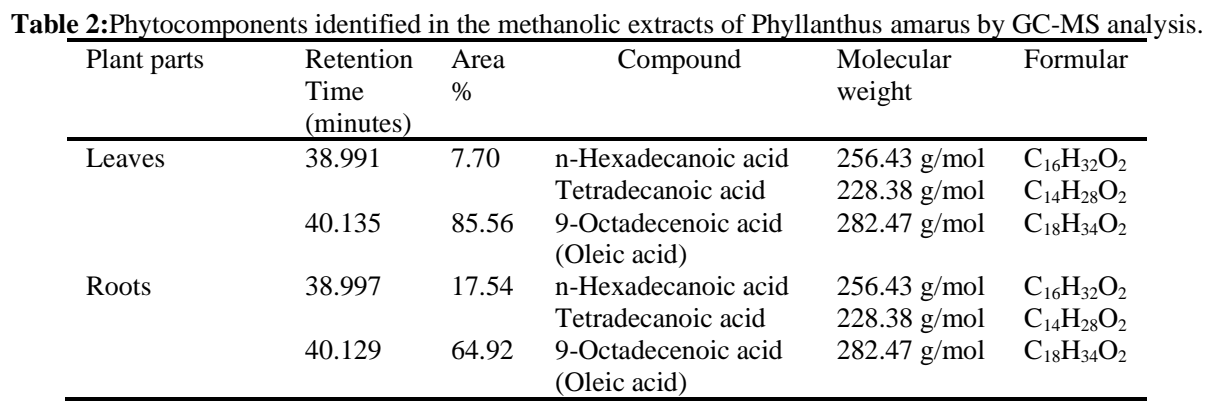

Mass spectrometry coupled with chromatographic separations such as Gas chromatography (GC-MS) is normally used for direct analysis of components existing in traditional medicines and medicinal plants. Natarajan et al., 2014 investigated that GC-MS studies have been increasingly applied for the analysis of medicinal plants as this technique has proved to be a valuable method for the identification of non-polar components and volatile essential oil, fatty acids, and lipids. By this study analysis, 3 compounds each were identified in methanolic extract leaves and root of $P$. amarus. The plant was frequently utilized by traditional medicine for the treatment of several liver diseases. The use of this medicinal plant by man for the treatment of several diseases has been practiced for a very longer period of time. Ogunlesi et al., 2009 said that medicinal plant is used to treat jaundice as well as helps in the regeneration of cells. Apart from these properties, it has anti-bacterial effect, as reported by
(Akinjogunla et al., 2010). Using methanol as solvent, a recent study by Igwe and Okwunodulu (2014) reported six phytocomponents from the leaves of Phyllanthus amarus. The phytocomponents identified in their study were 9-octadecenoic acid (57.05\%) constituting the bulk of the oil followed by L-(+)ascorbic acid 2, 6-dihexadecanoate (22.54\%). Other compounds identified include n-hexadecanoic acid, tetradecanoic acid $(2.90 \%)$, hexadecanoic acid methyl ester $(1.25 \%)$ and tetradecanoic acid, 1-methylethyl ester $(1.07 \%)$. In an earlier study on Phyllanthus amarus, the authors reported that the methanolic extracts exhibited anti-oxidant activity leading to leptospiral DNA damage and mentioned about the possibility of the extracts anti-leptospiral activity. In another study conducted by Mamza et al., (2012) to investigate bioactive components of methanolic extract of $P$. amarus using GC-MS analysis; the authors identified seven components namely palmitic 
acid (hexadecanoic acid) (11.8\%), 10-octadecanoate (5.5\%), 9-hexadecenal (9.0\%), glycerol 1, 3dipalmitate $(5.7 \%), 2$, 13-octadecadiene-1-ol (8.2\%), dioctyl ester $(10.1 \%)$ and heptadecanoic acid (4.6\%). This study is in agreement with the present study on the plants methanolic extraction procedure. However, the plant derived compounds were ignored of their therapeutic values which are mostly secondary plant metabolites traditionally used for medicinal purposes. They have a wide range of activity and may contain different categories of active principles.

Conclusion: The GC-MS analysis of methanol extracts of the leaves and root of $P$. amarus revealed the presence of three medicinally important bioactive compounds, which are: 9-Octadecenoic acid, nHexadecanoic acid and Tetradecanoic acid in the leaves and roots of $P$. amarus. These analytical results suggest the plant possess a significant role in phytomedicine.

\section{REFERENCES}

Adegoke, AA; Iberi, PA; Akinpelu, DA; Aiyegoro, P (2010). Studies on phytochemical screeningand antimicrobial potentials of Phyllanthusamarusagainst multiple antibiotic resistant bacteria”. Int. J. Appl. Res. Nat. Prod. 3:6

Adeneye, AA; Amole, OO; Adeneye, AK (2006). Hypoglycemic and hypocholesterolemic activities of the aqueous leaf and seed extract of Phyllanthus amarus in mice. Fitoterapia. 77: 511514

Akinjogunla, OJ; Eghafona, NO; Enabulele, IO; Mboto, CI; Ogbemudia, FO (2010). Antibacterial activity of ethanolic extracts of Phyllanthus amarus against extended spectrum lactamase producing Escherichia coli isolated from stool samples of HIV sero-positive patients with or without diarrhea". Afr. J. Pharm. Pharmacol. 4:402-407.

Amelio, SOF (1999). Botanical: A Phytochemical Disk Reference, C. R. C Press, Washington D. C.

Casley-Smith, JR (1993). Treatment of lymphedema of the arms and legs with 5, 6-benzo-(alpha)pyrone. NEJM. 329(16): 1158-63

Cushnie, TP;Cushnie, B; Lamb, AJ (2014). Alkaloids: An overview of their antibacterial, antibioticenhancing and anti-virulence activities". Int $J$. antimicr. Agent. 44(5):377-386
Davis, PH; Heywood, VH (2013). "Principles of Angiosperm Taxonomy". Oliver and Boyd, Edinburgh. 20: 13

Finar, IL (1989). Chemistry, Stereochemistry and the chemistry of Natural products". 5 $5^{\text {th }} \mathrm{Edn}$, Vol. 2. Longman group, UK. p.517-605

Igwe, OU; Okwunodulu, FU (2014). "Investigation of bioactive phytochemical compounds from the choloroform extract of the leaves of Phyllanthus amarus by GC-MS technique". IJCPS. 2: 554-560

Itoro, E; Ukana, D; Ekaete, D (2013). "Phytochemical screening and nutrient analysis of Phyllanthus amarus". Asian J. Plant Sci. Res. 3:116-122

Jimoh, FO; Oladiji, AT (2005). "Preliminary studies on Pilostigmathon ningii seed: proximate analysis, medicinal composition and phytochemical screening. Afr. J. Biotechnol. 4(12):1439-1442

Kittakoop, P; Mahidol, C;Ruchirawat, S (2014). Alkaloids as important Scaffolds in therapeutic drugs for the treatments of cancer, tuberculosis and smoking cessation. Curr. Top Med. Chem. 14(2): 239-252.

Lai, PK; Roy, J; (2004). Antimicrobial and Chemopreventive properties of herbs and spices. Curr. Med Chem. 11(11):145-60.

Mamza, UT; Sodipo, OA; Khan, IZ (2012). Gas chromatography-mass spectrometry (GC-MS) analysis of bio active components of $P$. amarus leaves. Int. Res. J.Plant Sci. 3: 208-215.

Mazumder, A;Mahato, A; Mazumder, R (2006). Antimicrobial potentiality of Phyllanthus amarus against drug resistant pathogens. Nat. Prod. Res.20(4):323-326

Muthulakshmi, A; Margret, J;R.andMohan V. R. (2012). GC- MS Analysis of Bioactive components of Feoniaelephan tumcorrea (Rutaceae). J. App. Pharm. Sci. 2 (2):69- 74

Natarajan, D; Srinivasan, R; Shivakumar, MSP; Wightianus, M (2014). Arg: A potential source for natural anti-microbial agents". Biomed. Res. Inter. Article ID- 135082. 1-9.

Ogunleye, DS; Ibitoye, SF (2003). Studies of antimicrobial activity and chemical constituents 
of Ximena Americana. Trop. J. Pharm.Res.2: 239-241.

Odetola, A.A; Akojenu, S.M (2000). Antidiarrhoeal and gastro-intestinal potential of the aqueous extract of Phyllanthus amarus (Euphorbiaceae)". Afr. J. Med. Sci. 29: 119-22.

Ogunlesi, M; Okiei, W; Osibote, EAS; Muotoh, C (2009). Antimicrobial activity of the essential oil and the fractional samples obtained from the leaves and seeds of Phyllanthusamarus (Euphorbiaceae). Res. J. Phytochem. 3: 77-84.

Okwu, DE (2003). The potentials of Ocimum gratissimum, Pengularia extrensa and Tetrapleuratetraptera as spice and flavouring agents. Nig. Agric. J. 34:143-148.

Okwu, DE; Emenike, IN (2006). Evaluation of the phytonutrients and vitamin contents of Citrus fruits. Int. J. Mol. Med. and Adv. Sci. 2(1):1-6.

Okwu, DE; Omodamino, OD (2005). Effects of hexane extract and phytochemical content of Xylopia aethiopica and Ocimum gratissimumon uterus of guinea pig. Bio. Res. 3:40-44.

Okwu, DE (2004). "Phytochemicals and vitamin contents of indigenous species of South Eastern Nigeria.J. Sustain. Agric. Environ.6,30-37.
O’Neil, L; Kim-Standage, WS, Hughes, GB; Murray, KB (2000). Vegetables, Fruits and Herbs in Health Promotion”, C. R. C. Press, USA.

Qiu, S; Sun, H; Zhang, AH; Xu, HY; Yan, GL; Han, Y; Wang, XJ (2014). Natural alkaloids: basic aspects, biological roles, and future perspectives. Chin. J. Nat. Med. 12(6): 401-406

Robbers, JE; Speedie, Mk.; Tyler, VE (1996).: Alkaloids. Pharmacognosy and Pharmaco biotechnology. Philadelphia: Lippincott, Williamsand Wilkins. p143-185.

Tahseen, M; Mishra, G (2013). Ethnobotany and Diuretic Activity of Some Selected Indian Medicinal Plants. Pharm.Innov. 2:112

Tapsell, LC;Hamphill, I; Cobiac, L (2006).Health benefits of herbs and spices: The past, the present, the future. Med. J. Augt. 185(4):14-24

Zaidan, M; Rin, N; Badrul, A (2005). In vitro screening of ive local medicinal plants for antibacterial activity using disc diffusion method. Trop. Biomed. 22:165- 170.

Zingare, A (2013). Antimicrobial activity of six members of Euphorbiaceae". New Interdiscip. National Res. J. 2:112. 